\title{
Characterizing the Passage of Personal Care Products Through Wastewater Treatment Processes
}

\author{
Joan Oppenheimer*, Roger Stephenson, Arturo Burbano, Li Liu
}

\begin{abstract}
Wastewater treatment facilities use secondary treatment to stabilize the effect of discharged effluent on receiving waters by oxidizing biodegradable organic matter and reducing suspended solids and nutrients. The process was never specifically intended to remove trace quantities of xenobiotics, such as endocrine-disrupting compounds (EDCs) and pharmaceuticals and personal care products (PPCPs). Nevertheless, European studies performed at bench-scale or at small facilities have demonstrated that a critical minimum solids retention time (SRT) can achieve good reduction of many EDCs and pharmaceuticals. The objective of this study was to expand these findings to the removal performance for 20 PPCPs commonly found in the influent to full-scale facilities operating in the United States. The participating plants use SRT conditions ranging from 0.5 to 30 days and include facility capacities ranging from $19000 \mathrm{~m}^{3} / \mathrm{d}(5 \mathrm{mgd})$ to greater than $1136000 \mathrm{~m}^{3} / \mathrm{d}$ (300 mgd). Two pilot membrane bioreactors were also included in the study.

The 20 PPCPs were categorized into nine bin combinations of occurrence frequency and treatment reduction performance. While most compounds were well removed, galaxolide (a musk fragrance) occurred frequently and was resistant to removal. A minimum critical SRT, defined as the minimum SRT, needed to consistently demonstrate greater than $80 \%$ removal $\left(\mathrm{SRT}_{80}\right)$, was compound-dependent, with most compounds removed at 5 to 15 days and a small group requiring longer SRTs. From limited data, no additional removal could be attributed to the use of membrane bioreactors, media filters, or longer hydraulic retention times. Reverse osmosis was effective in removing any remaining compounds. Water Environ. Res., 79, 2564 (2007).
\end{abstract}

KEYWORDS: personal care products, secondary treatment, solids retention time, full-scale treatment plants.

doi: $10.2175 / 106143007 X 184573$

\section{Introduction}

Municipal wastewater treatment facilities in the United States must comply with discharge limits for biochemical oxygen demand, total suspended solids (TSS), and other conventional pollutants. The core treatment used at these facilities is biological secondary treatment, with most metropolitan facilities using an activated sludge process. Supplemental or enhanced treatment is practiced at facilities subject to more stringent discharge requirements or those that produce effluent for reuse applications. It is anticipated that regulations promulgated in the future may add new compounds of concern to the regulatory list, based on the availability of sufficient evidence (i.e., occurrence and toxicological studies) to justify their inclusion (Halling-Sǿrenson et al., 1998).

Among the compounds that may become regulated in the future, natural and synthetic chemicals, collectively known as endocrine-

Montgomery Watson Harza, Arcadia, California.

*618 Michillinda Ave., Arcadia CA 91007; e-mail: joan.oppenheimer@ mwhglobal.com. disrupting compound (EDCs) and pharmaceutical and personal care products (PPCPs), are potential candidates. Studies supporting the theory that some of these chemicals can mimic the activity of natural endocrine hormones have existed for more than 70 years, and target these compounds as suspected causative agents of reported episodes of disruption in wildlife reproductive health (Snyder et al., 2003). Although contamination from these chemicals may originate from nonpoint sources, a significant fraction comes from municipal wastewater treatment plants (WWTPs) (Daughton and Ternes, 1999). Municipal WWTPs act as persistent point sources of EDCs and PPCPs, and trace concentrations of these chemicals have been observed in conventional secondary and tertiary wastewater discharges in the United States and abroad (Clara et al., 2005; Eriksson et al., 2003; Joss et al., 2004; Snyder et al., 2001).

The EDCs and PPCPs have not been subject to scrutiny in the past, mostly because of analytical limitations that prevented accurate detection and quantification of trace concentrations of these compounds (Ollers et al., 2001; Osemwengie and Steinberg, 2001). The advancement of analytical techniques, such as gas chromatography and liquid chromatography with tandem mass spectroscopy, now allow identification and quantification of these compounds at micrograms per liter (parts per billion) or nanograms per liter (parts per trillion) concentrations (Sedlak et al., 2000).

The presence of EDCs and PPCPs in the environment may pose a complex problem for two main reasons-(1) their effects are likely to occur at trace concentrations, and (2) their presence in effluent from municipal WWTPs is mostly the result of unregulated activities of individuals rather than regulated industrial discharges (Daughton and Ternes, 1999; Snyder et al., 2001). Consequently, understanding the ability of conventional wastewater treatment plants to prevent the passage of these compounds into the environment has become a critical concern (Clara et al., 2004).

Extensive research has been conducted to evaluate the occurrence and fate of hormonal EDCs in the environment. Estrogenic hormones (i.e., estradiol, estrone, and ethinyl estradiol), in particular, have been the focus of multiple studies, as they have been related to ubiquitous episodes of intersex in male fish in multiple locations in the United States and Europe (Irwin, 1998; Snyder et al., 2004; Ternes et al., 1999). Synthetic PPCPs remain a category considerably less studied, and comprehensive information on manufacturing, use, and disposal of these chemicals into the environment is less readily available. The findings of a United States Geological Survey (Reston, Virginia) reconnaissance survey of United States urban area streams (Kolpin et al., 2002) and other studies (Eriksson et al., 2003) have recently demonstrated the 
Table 1-Description of participating treatment facilities.

\begin{tabular}{|c|c|c|c|c|c|c|c|c|c|}
\hline Facility & $\begin{array}{c}\text { Wastewater } \\
\text { type }\end{array}$ & $\begin{array}{l}\text { Primary } \\
\text { treatment }\end{array}$ & $\begin{array}{l}\text { Secondary } \\
\text { treatment }\end{array}$ & $\begin{array}{l}\text { Secondary } \\
\text { aeration }\end{array}$ & $\begin{array}{l}\text { MLSS } \\
\text { (mg/L) }\end{array}$ & $\begin{array}{l}\mathrm{SRT}^{\mathrm{b}} \\
\text { (days) }\end{array}$ & Filters & Disinfection & $\begin{array}{l}\text { Nitrification/ } \\
\text { denitrification } \\
\text { performance }\end{array}$ \\
\hline C & $\begin{array}{l}\text { Municipal } \\
\text { with light } \\
\text { industrial } \\
\text { component }\end{array}$ & $\begin{array}{l}\text { No } \\
\text { chemicals }\end{array}$ & $\begin{array}{c}\text { Activated } \\
\text { sludge }\end{array}$ & Diffused air & $\begin{array}{c}2000 \text { to } \\
3000\end{array}$ & 4 to 6 & Deep bed ${ }^{C}$ & UV & $\begin{array}{l}\text { Partial } \\
\text { nitrification } \\
\text { Partial } \\
\quad \text { denitrification }\end{array}$ \\
\hline E & $\begin{array}{l}\text { Municipal } \\
\text { with light } \\
\text { industrial } \\
\text { component }\end{array}$ & None & $\begin{array}{l}\text { Nitrification/ } \\
\text { denitrification }\end{array}$ & Diffused air & 2100 & 11 to 16 & None & UV & $\begin{array}{l}\text { Full } \\
\quad \text { nitrification } \\
\text { Partial } \\
\quad \text { denitrification }\end{array}$ \\
\hline F & $\begin{array}{l}\text { Municipal } \\
\text { with light } \\
\text { industrial } \\
\text { component }\end{array}$ & None & $\begin{array}{l}\text { Extended } \\
\text { aeration } \\
\text { nitrification/ } \\
\text { denitrification }\end{array}$ & Surface air & 4000 & 20 to 30 & Deep bed ${ }^{C}$ & UV & $\begin{array}{l}\text { Full } \\
\text { nitrification } \\
\text { Full } \\
\quad \text { denitrification } \\
{ }^{\mathrm{m}}\end{array}$ \\
\hline MBR \#01 $1^{\mathrm{d}, \mathrm{e}}$ & $\begin{array}{l}\text { Municipal } \\
\text { with light } \\
\text { industrial } \\
\text { component }\end{array}$ & $\begin{array}{l}\text { Not } \\
\text { applicable }\end{array}$ & $\begin{array}{l}\text { Nitrification/ } \\
\text { denitrification }\end{array}$ & $\begin{array}{l}\text { Not } \\
\text { applicable }\end{array}$ & 14000 & 14 & $\begin{array}{l}\text { Not } \\
\text { applicable }\end{array}$ & $\begin{array}{l}\text { Not } \\
\text { applicable }\end{array}$ & $\begin{array}{l}\text { Full } \\
\text { nitrification } \\
\text { Almost no } \\
\text { denitrification }\end{array}$ \\
\hline MBR \#02,g & $\begin{array}{l}\text { Municipal } \\
\text { with light } \\
\text { industrial } \\
\text { component }\end{array}$ & $\begin{array}{l}\text { Not } \\
\quad \text { applicable }\end{array}$ & Not applicable & $\begin{array}{l}\text { Not } \\
\quad \text { applicable }\end{array}$ & 11500 & 15 & $\begin{array}{l}\text { Not } \\
\quad \text { applicable }\end{array}$ & $\begin{array}{l}\text { Not } \\
\quad \text { applicable }\end{array}$ & $\begin{array}{l}\text { 1st sampling: } \\
\text { Partial } \\
\text { nitrification } \\
\text { Partial } \\
\text { denitrification. } \\
\text { 2nd sampling: } \\
\text { Almost no } \\
\text { nitrification } \\
\text { Almost no } \\
\text { denitrification. }\end{array}$ \\
\hline
\end{tabular}

\footnotetext{
a MLE (Modified Ludzack Ettinger Process),

${ }^{b}$ Reported SRT corresponding to total from combined aerobic/anoxic facilities (in plants with nitrification/denitrification),

${ }^{c}$ Granular media,

d Uses flat sheet membranes,

e Located at plant E,

${ }^{\dagger}$ Uses free-end hollow fiber membranes,

g Located at a facility not listed above,

${ }^{\mathrm{h}}$ Almost no nitrification $=<15 \%$ ammonia removal,

'Almost no denitrification $=<15 \%$ total inorganic nitrogen removal,

'Partial nitrification $=15$ to $90 \%$ ammonia removal,

${ }^{\mathrm{k}}$ Partial denitrification $=15$ to $90 \%$ total inorganic nitrogen removal, and

' Full nitrification $=>90 \%$ total ammonia removal.

${ }^{m}$ Full nitrification $=>90 \%$ total inorganic nitrogen removal.
}

widespread environmental occurrence of PPCP compounds. These findings have generated public concern about the presence of trace concentrations of these chemicals in the environment (Daughton and Ternes, 1999; Wilson et al., 2003). Some subset of these compounds may ultimately classify as EDCs.

This study surveyed a target list of PPCP compounds, representing a range of chemical characteristics that have routinely been detected in wastewater influent, and assessed the removal of these parent compounds from the aqueous phase of the secondary effluent of the conventional secondary treatment facilities. The data were then evaluated to determine if the removals of these compounds are influenced by the solids retention time (SRT), which is a major variable in the design and operation of activated sludge secondary treatment. In addition, PPCP removal through subsequent tertiary media 


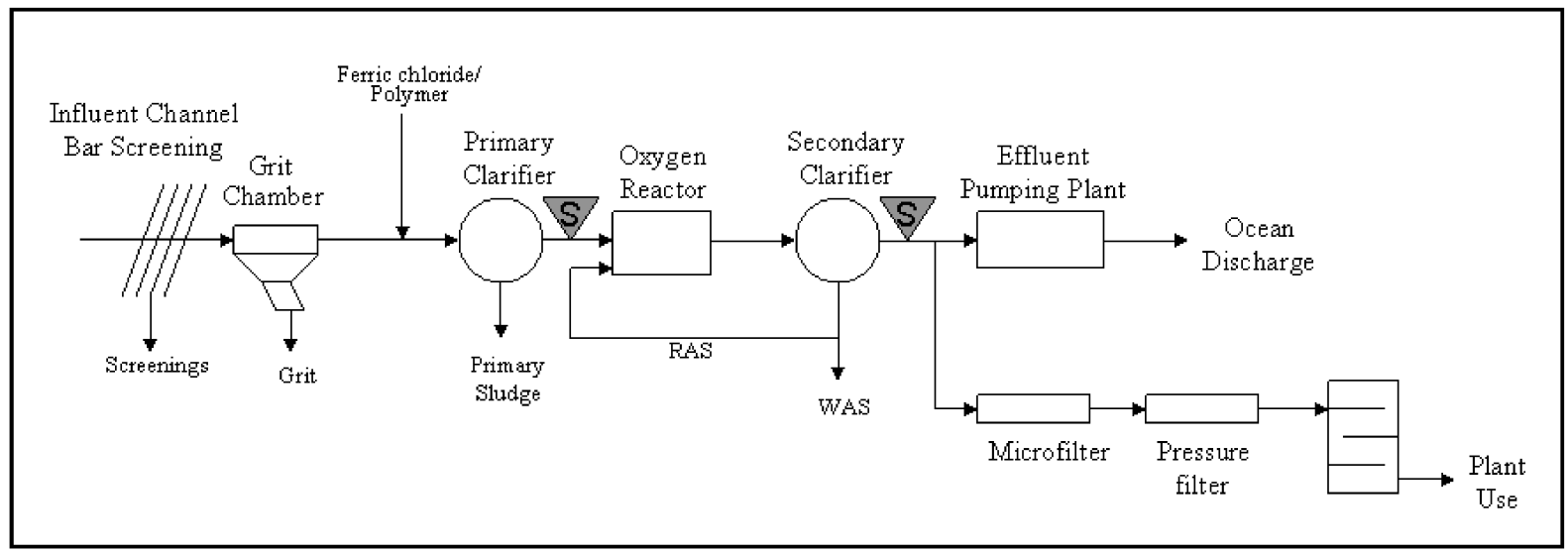

Plant A (SRT 0.5 to 1.5 days $)$

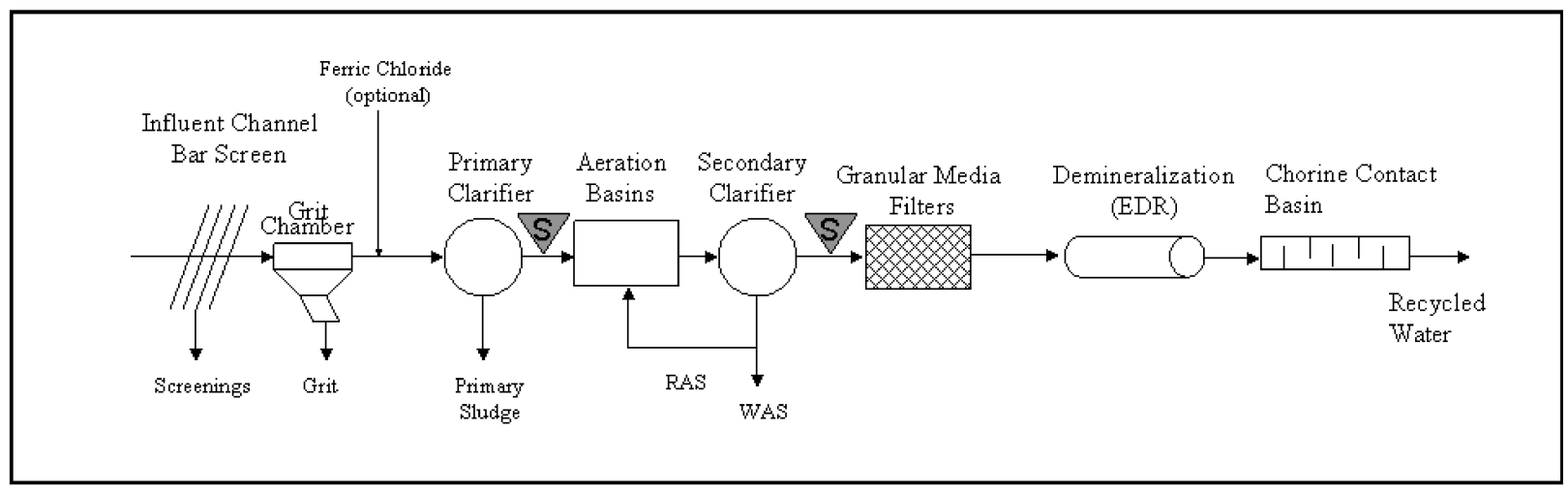

Plant B (SRT 3 to 5 days)

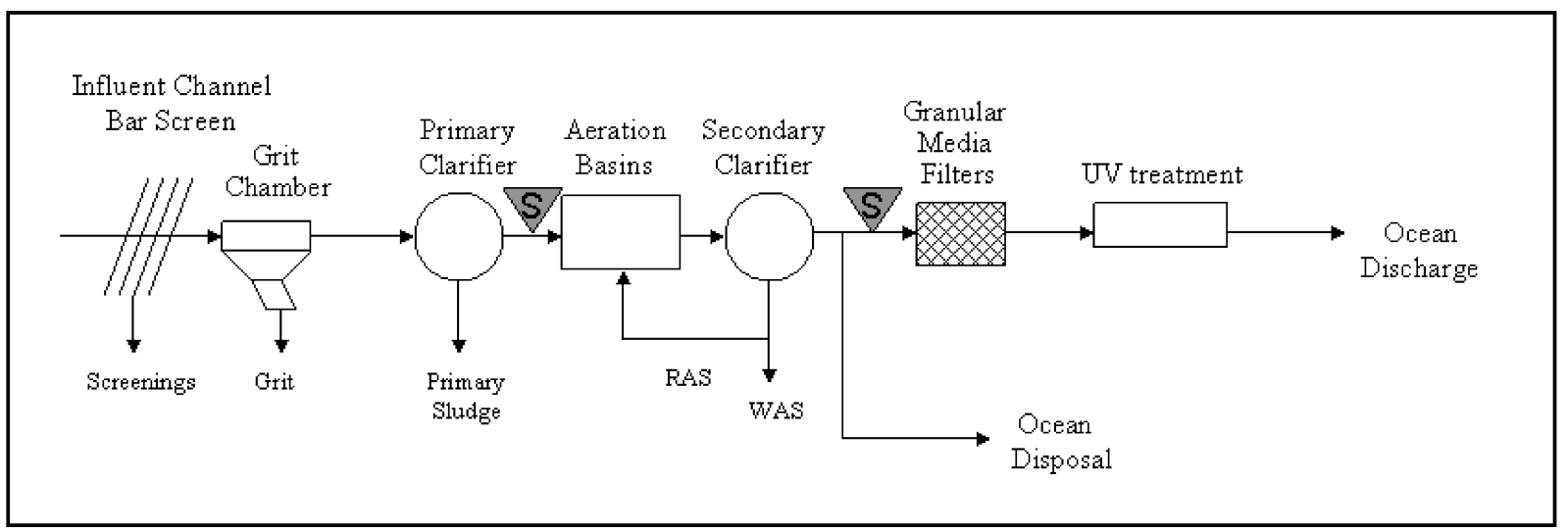

Plant C (SRT 5 to 6 days)

Figure 1-Schematics of participating full-scale facilities (RAS = return activated sludge, WAS = waste activated sludge, and EDR = electrodialysis reversal).

filtration and disinfection and newer hybrid treatment processes, such as membrane bioreactors (MBRs), were also evaluated.

Extended SRTs promote the growth of a more diverse biological community that is able to degrade xenobiotic compounds more efficiently because of co-metabolic effects (Grady et al., 1980). It has been reported that increasing SRT has a beneficial effect on the removal of xenobiotic compounds (Clara et al., 2005; Joss et al., 2004; Kanda et al., 2003; Kreuzinger et al., 2004; Ternes et al., 1999). These data also suggest the existence of a critical SRT value, after which, the removal of these compounds is not improved (Clara 


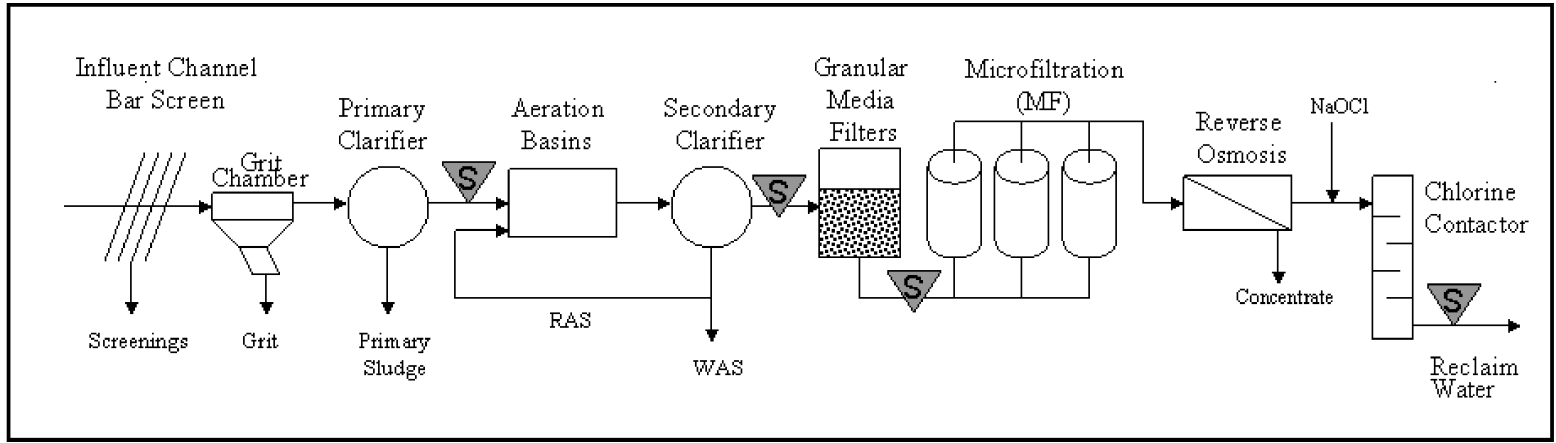

Plant D (SRT $\sim 7$ to 20 days)

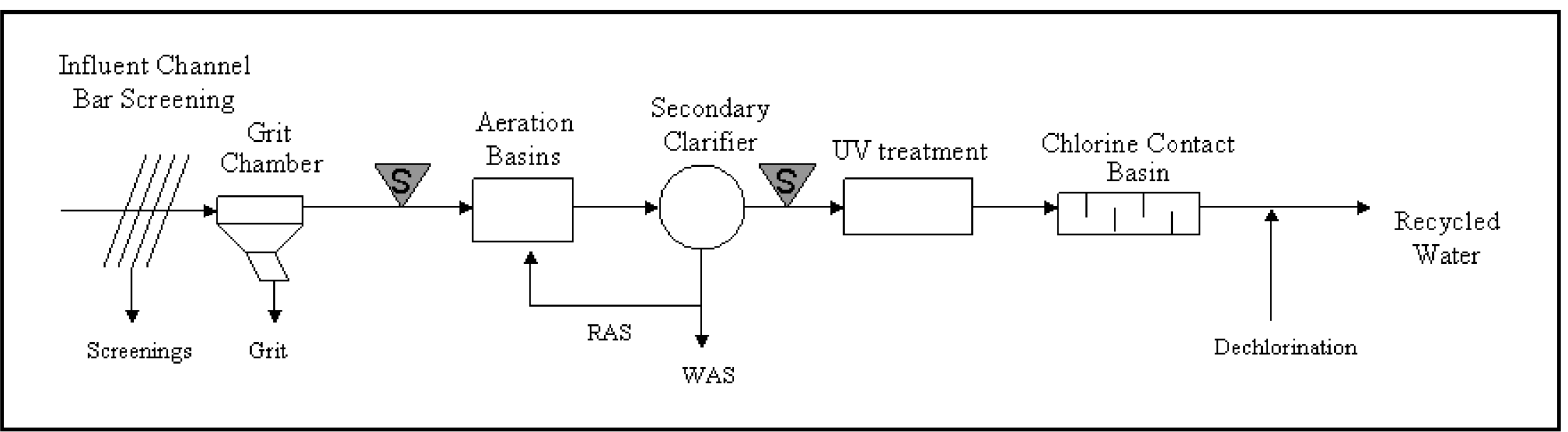

\section{Plant E (SRT 11 to 16 days)}

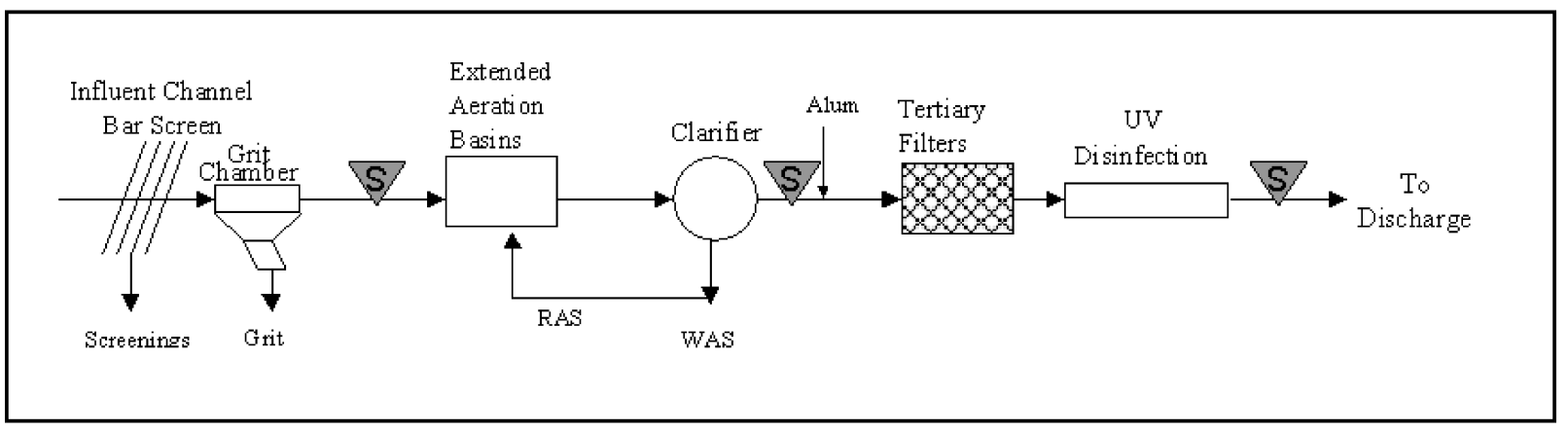

\section{Plant F (SRT 25 to 30 days)}

\section{Figure 1-(Continued)}

et al., 2005; Joss et al., 2004). These conclusions have been derived from studies conducted at small-scale WWTPs and bench/pilot studies performed under controlled conditions. Many of these studies were conducted in Europe and have been more focused on estrogens and prescription pharmaceuticals than personal care products (Andersen et al., 2003; Kreuzinger et al., 2004; Ternes et al, 1999). For this reason, one of the main objectives of this research is to validate these conclusions using data from a group of large-scale WWTPs located in the United States, which includes facilities with capacities as high as $1325000 \mathrm{~m}^{3} / \mathrm{d}(350 \mathrm{mgd})$. This study provides a systematic analysis of the effect of SRT on PPCP removal, by analyzing data from six full-scale WWTPs and two pilot-scale MBRs operating over a wide range of SRT values. Development of this information may prove valuable in defining optimum operational parameters for existing WWTPs and the design of future installations, from the perspective of PPCP removal. This study will help utilities to better address growing public concerns about PPCPs (Joss et al., 2004), by identifying those compounds resistant to removal and define critical SRT values where good removal is achieved. 
Table 2-General characteristics of the analytical methods used in this study.

\begin{tabular}{|c|c|c|c|c|c|c|c|}
\hline Compound & $\begin{array}{l}\text { Retention } \\
\text { time } \\
\text { (minutes) }\end{array}$ & $\begin{array}{c}\text { Major } \\
\text { ion }(\mathrm{m} / \mathrm{z})\end{array}$ & Segment & $\begin{array}{c}\text { Spiked } \\
\text { concentration } \\
(\mu \mathrm{g} / \mathrm{L})\end{array}$ & $\begin{array}{c}\text { Baseline } \\
\text { concentration* } \\
(\mu \mathrm{g} / \mathrm{L})\end{array}$ & $\begin{array}{l}M D L \\
(\mu g / L)\end{array}$ & $\begin{array}{c}\text { Ratio of MDL } \\
\text { to initial } \\
\text { concentration }\end{array}$ \\
\hline 3-phenyl propionate & 13.2 & 150 & 1 & 0.50 & 2.43 & 10.7 & 3.64 \\
\hline Ethyl 3-phenyl propionate & 13.2 & 178 & 1 & 0.05 & $\mathrm{BDL}$ & 0.012 & 0.25 \\
\hline Chloroxylenol & 13.7 & 156 & 1 & 0.05 & $\mathrm{BDL}$ & 0.015 & 0.29 \\
\hline DEET & 16.1 & 190 & 2 & 0.05 & 0.189 & 0.086 & 0.36 \\
\hline Ibuprofen & 16.5 & 163 & 2 & 1.0 & BDL & 1.44 & 1.44 \\
\hline Benzophenone & 16.8 & 182 & 2 & 0.05 & 0.112 & 0.043 & 0.27 \\
\hline $\begin{array}{l}\text { Dibromooctafluorebiphenyl_-internal } \\
\text { standard }\end{array}$ & 17.3 & & $\mathrm{TIC}$ & & & & \\
\hline Tri(2-chloroethyl)phosphate & 18.1 & 249 & 3 & 0.05 & 0.302 & 0.179 & 0.51 \\
\hline Musk ketone & 20.4 & 279 & 4 & 0.01 & 0.065 & 0.034 & 0.45 \\
\hline Oxybenzone & 20.9 & 227 & 4 & 0.01 & 0.083 & 0.06 & 0.65 \\
\hline Triclosan & 21.7 & 290 & 4 & 0.05 & 0.19 & 0.35 & 1.44 \\
\hline Octyl methoxycinnamate & 22.1 & 178 & 4 & 0.01 & 0.074 & 0.11 & 1.28 \\
\hline Butyl benzyl phthalate & 23.7 & 206 & 5 & 0.01 & 0.142 & 0.13 & 0.88 \\
\hline Triphenyl phosphate & 24.3 & 326 & 5 & 0.5 & $\mathrm{BDL}$ & 0.62 & 1.24 \\
\hline 2,4-dichlorophenol- $d_{3}-$ surrogate & 10.7 & 165 & $\mathrm{TIC}$ & & & & \\
\hline Caffeine $-{ }^{13} \mathrm{C}_{3}$ - surrogate & 19.1 & 197 & 3 & & & & \\
\hline 3,3-dichlorobenzidine-d6-surrogate & 25.2 & 258 & $\mathrm{TIC}$ & & & & \\
\hline Di(ethylhexyl) phthalate- $d_{4}$ - surrogate & 26.1 & 283 & $\mathrm{TIC}$ & & & & \\
\hline
\end{tabular}

${ }^{*} \mathrm{BDL}=$ below detection limit.

\section{Methodology}

Participating Facilities and Sampling Protocols. Unit process descriptions, secondary operating characteristics, wastewater type, and performance of nitrification/denitrification processes corresponding to the six participating full-scale facilities and two pilot MBRs are provided in Table 1. Process schematics of the fullscale facilities, indicating specific sampling locations, are presented in Figure 1.

Table 3-Compound occurrence bin assignment and 50th percentile concentration.

\begin{tabular}{|c|c|c|c|}
\hline $\begin{array}{l}\text { Occurrence } \\
\text { bin name }\end{array}$ & Bin assignment criteria & Compounds & $\begin{array}{c}\text { 50th percentile } \\
\text { value (ng/L) }\end{array}$ \\
\hline Infrequent & Detected in $<25 \%$ of the observations & $\begin{array}{l}\text { TCEP } \\
\text { Octylphenol } \\
\text { Methyl-3-phenylpropionate } \\
\text { Triphenylphosphate }\end{array}$ & $\begin{array}{l}\text { Not detected } \\
\text { Not detected } \\
\text { Not detected } \\
\text { Not detected }\end{array}$ \\
\hline Variable & Detected between 40 and $70 \%$ of the observations & $\begin{array}{l}\text { DEET } \\
\text { Ethyl-3-phenylpropionate } \\
\text { BHA } \\
\text { Musk ketone }\end{array}$ & $\begin{array}{l}120 \\
26 \\
\text { Not detected } \\
70\end{array}$ \\
\hline Frequent & Detected in $>75 \%$ of the observations & $\begin{array}{l}\text { Chloroxylenol } \\
\text { Benzyl salicylate } \\
\text { Galaxolide } \\
\text { Triclosan } \\
\text { Benzophenone } \\
\text { Octylmethoxycinnamate } \\
\text { Oxybenzone } \\
\text { Butylbenzylphthalate } \\
\text { Caffeine } \\
\text { Methylparaben } \\
\text { 3-Phenylpropionate } \\
\text { Ibuprofen }\end{array}$ & $\begin{array}{l}520 \\
450 \\
1850 \\
5200 \\
940 \\
1400 \\
1870 \\
2000 \\
1900 \\
2950 \\
205000 \\
6300\end{array}$ \\
\hline
\end{tabular}


Table 4-Compound removal bin assignment.

\begin{tabular}{ccl}
\hline $\begin{array}{c}\text { Removal } \\
\text { bin name }\end{array}$ & $\begin{array}{c}\text { Bin assignment } \\
\text { criteria }(\mathbf{X}=\text { median } \\
\text { percent removal value) }\end{array}$ & \multicolumn{1}{c}{ Compounds } \\
\hline $\begin{array}{c}\text { Excellent } \\
\text { removal }\end{array}$ & $X>80 \%$ & $\begin{array}{l}\text { Methyl-3-phenylpropionate* } \\
\text { Caffeine } \\
\text { lbuprofen }\end{array}$ \\
& & Oxybenzone \\
& & Chloroxylenol \\
& & Methylparaben \\
& & Benzyl salicylate \\
& & 3-Phenylpropionate \\
& & Butylbenzyl phthalate \\
& & Octylmethoxycinnamate \\
& Benzophenone \\
Moderate & $50 \%<x<80 \%$ & Octylphenol* \\
removal & & Ethyl-3-phenylpropionate \\
& & Triclosan \\
Poor & & TCEP* \\
removal & & Triphenylphosphate* \\
& & BHA \\
& & DEET \\
& & Musk ketone \\
& & Galaxolide \\
& &
\end{tabular}

* Treatment classification of compounds from the infrequent occurrence bin is limited by insufficient data, as they were seldom detected in the influent.

This study evaluates contaminant removal through secondary treatment. Water quality information for the influent to secondary treatment was obtained from primary effluent or from raw influent, depending if the plant has primary treatment or not. One of the tested MBRs was equipped with submerged flat sheet membranes arranged in cassettes (Kubota Submerged Membrane Unit, Kubota Corporation, Osaka, Japan), and the other consisted of submerged free-end hollow fiber membranes (Koch/Puron, Koch Membrane Systems, Wilmington, Massachusetts). Both were operated in accordance with vendor specified conditions for at least two SRTs before sample collection. Samples were collected from the majority of these facilities during three discrete sampling events.

Secondary influent (i.e., primary effluent) and secondary effluent samples were collected as 24-hour time-weighted composites during typical facility operations using three project-dedicated temperature controlled Glacier composite samplers (Teledyne ISCO, Lincoln, Nebraska). Granular media filtration effluent samples were also collected at facilities D and F, and microfiltration/reverse osmosis effluent samples were also collected at facility F. Samples were collected following the application of any chemical disinfectant applied at the sampling location. The Glacier sampling chest and all associated sampling materials were subject to three rounds of chemical cleaning with acetone and hexane before initiating the sampling process. Handling of all equipment was performed only while wearing powder-free nitrile gloves that were replaced with new gloves at the start of each sampling event.

Each composite sample had a total volume of approximately $10 \mathrm{~L}$, from which, $2 \mathrm{~L}$ were transferred to amber glass sample bottles with Teflon-lined caps and shipped overnight on ice to the analytical laboratory for PPCP analysis. The remaining sample volume was sent to a certified laboratory (Applied Physics and Chemistry Laboratory, Chino, California), for analysis of conven-

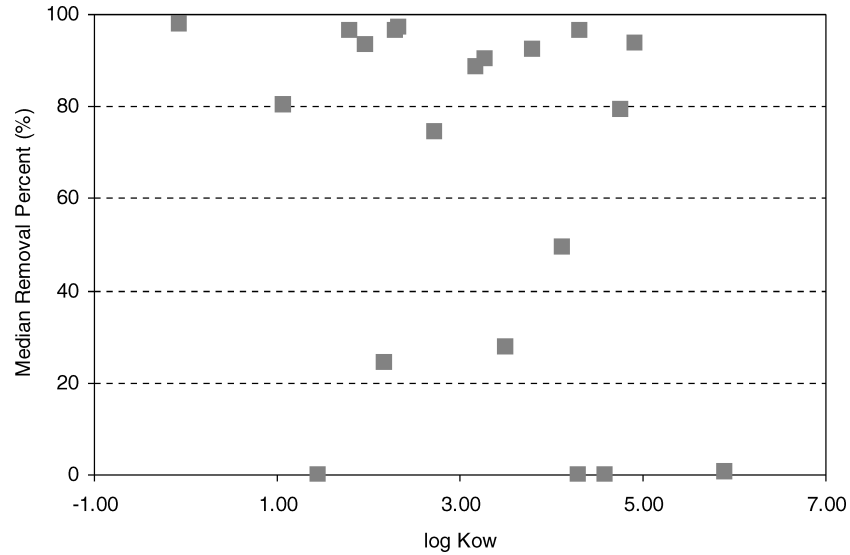

Figure 2-Median removal percentage of PPCP compounds in relation to the octanol-water partition coefficients.

tional constituents (TSS, volatile suspended solids, total Kjeldahl nitrogen, nitrate-nitrogen, nitrite-nitrogen, and ammonia-nitrogen). These data were only used when on-site plant data for these parameters were not available. At each sampling event, one blank and one duplicate split sample were collected and shipped for analysis. The blank consisted of running sufficient laboratory-grade distilled water through one of the sampling devices before sample collection at each sampling event. This water was then transferred to a separate amber glass bottle and shipped with the rest of the samples for analysis. The duplicate split sample location was randomly rotated during sampling events at each facility. No corrections were made to the sample data based on the results obtained for the blank and split samples.

Target Compounds and Analytical Methods. Samples were analyzed for PPCPs using solid-phase extraction (SPE) followed by analysis with a Perkin Elmer Clarus 500 gas chromatography/mass spectrometer (Perkin-Elmer, Waltham, Massachusetts) operated simultaneously in total ion count (TIC) and selective ion monitoring mode. Samples were initially refrigerated upon receipt and extracted, in most cases, within 24 hours. Samples were prefiltered through precleaned glass fiber filters (Fisher brand G8, 2.5-mm particle retention, and Fisher brand TCLP filter, 0.7-mm pore size; Fisher Scientific, Tustin, California). The filtrate was acidified with concentrated sulfuric acid to $\mathrm{pH}<2.0$. After acidification, aqueous samples were extracted using sulfonated polystyrene divinylbenzene SPE disks (3M Empore SDB-RPS; 3M, Minneapolis, Minnesota). The disks were precleaned with ethyl acetate and then conditioned per manufacturer's recommendation. The flowrate through the disk was maintained at less than $50 \mathrm{~mL} / \mathrm{min}$. The SPE disks were then eluted with acetone $(3 \mathrm{~mL})$ and a triple aliquot of ethyl acetate $(5 \mathrm{~mL})$. The eluate was dried over sodium sulfate, and the volume reduced to $0.5 \mathrm{~mL}$. The concentrate was transferred to a 2-mL gas chromatography vial sealed with screw caps, with polytetrafluoroethylene-coated rubber septa. 4,4Dibromooctafluorobipheyl (Supelco, Bellefonte, Pennsylvania) was added before analysis as an internal standard.

The gas chromatography method was as follows: $2.0 \mu \mathrm{L}$ injection, splitless, injector temperature $175^{\circ} \mathrm{C}, 40^{\circ} \mathrm{C}$ for 2 minutes, then $10^{\circ} \mathrm{C} / \mathrm{min}$ ramp to $250^{\circ} \mathrm{C}$, hold for 14 minutes, ramp to $290^{\circ} \mathrm{C}$ at a rate of $25^{\circ} \mathrm{C} / \mathrm{min}$, and hold for 2 minutes. The column was a RTX-MS5 $3 \mathrm{~m} \times 0.25 \mathrm{~m}$ internal diameter, $0.25-\mu \mathrm{m}$ film 

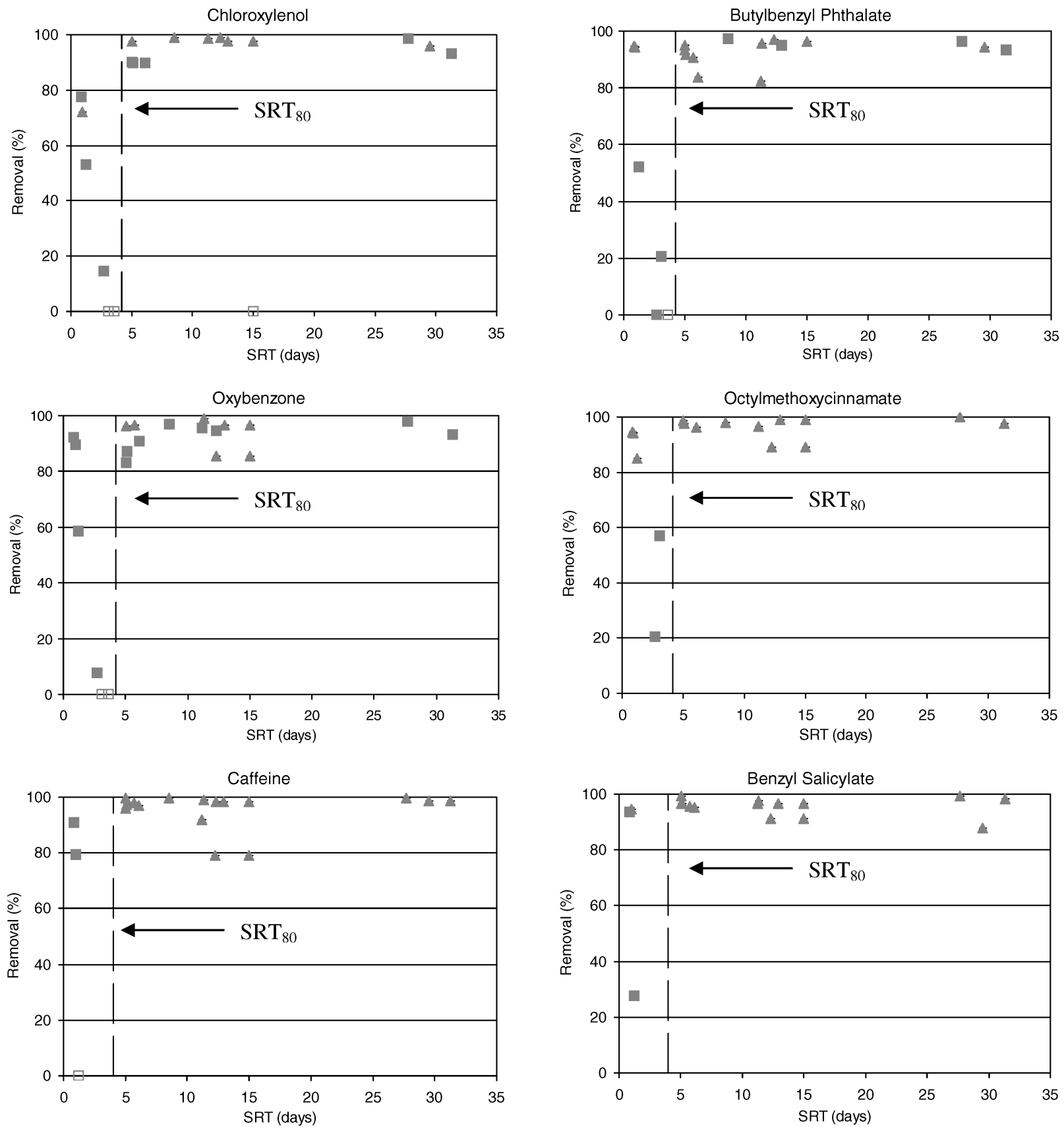

Figure 3-Percent removal in relation to SRT for excellent removal bin compounds $(\boldsymbol{\square}=$ actual removal, $\boldsymbol{\Delta}=$ removal greater than the percentage value presented, and $\square=$ effluent concentration greater than influent concentration).

thickness (Restek Corporation, Bellefonte, Pennsylvania). The TIC masses were scanned from 70 to $350 \mathrm{~m} / \mathrm{z}$ from 6 to 37 minutes. There were 5 selective ion response (SIR) segments, as follows:

(1) SIR 1 scans $150,156,164$, and $178 \mathrm{~m} / \mathrm{z}$ from 12.1 to 14.0 minutes;

(2) SIR 2 scans, 152, 163, 165, 182, and $190 \mathrm{~m} / \mathrm{z}$ from 14.0 to 17.2 minutes;

(3) SIR 3 scans 194, 197, 206, 228, 243, and $249 \mathrm{~m} / \mathrm{z}$ from 17.5 to 20.0 minutes;
(4) SIR 4 scans $178,227,279$, and $290 \mathrm{~m} / \mathrm{z}$ from 20.0 to 23.0 minutes; and

(5) SIR 5 scans 149,206 , and $326 \mathrm{~m} / \mathrm{z}$ from 23.0 to 26.5 minutes.

Retention times and monitored ions for the target compounds are listed in Table 2.

The materials used to prepare the standards were obtained from the following suppliers. The phthalate standards were prepared using EPA 525 Update Phthalate Ester Mix obtained from Supelco $(50 \mu \mathrm{g} / \mathrm{mL})$. The internal standard 4,4-dibromooctafluorobiphenyl was obtained from Supelco also. Ethyl 3-phenylproprionate (98\%), 

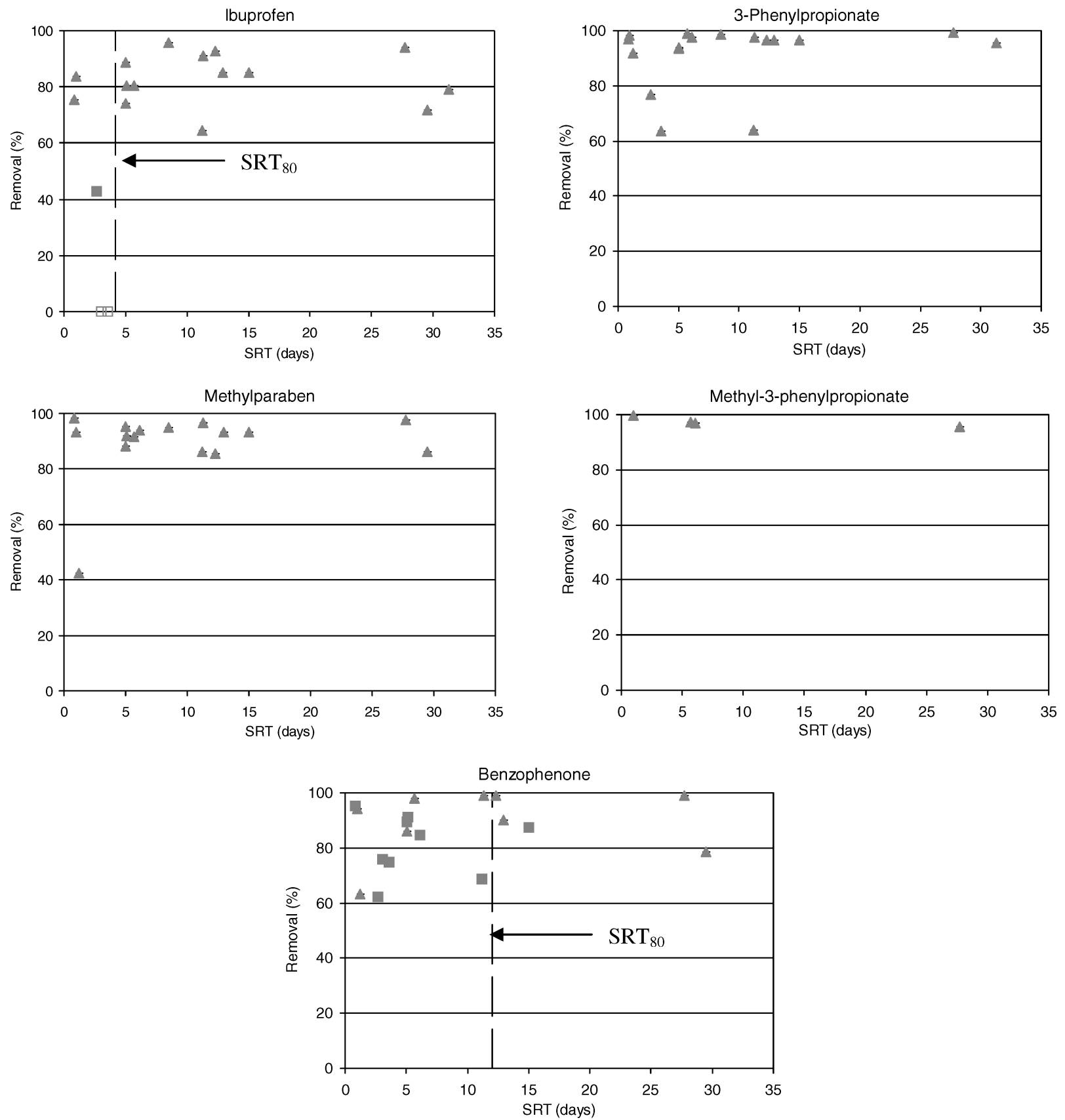

Figure 3-(Continued)

benzophenone (99\%), caffeine (98.5\%), benzyl salicylate (98\%), tris (2-chloroethyl) phosphate (97\%), butylated hydroxyanisole (96\%), 3-phenylpropionate (99\%), oxybenzone (98\%), and octyl methoxy cinnamate $(98 \%)$ were obtained from Acros (Allentown, Pennsylvania). Galaxolide (50\% in diethyl phthalate), 4-octyl phenol (99\%), musk ketone (98\%), methylparaben (National Formulary/Food Chemicals Codes), and chloroxylenol (99\%) were obtained from Sigma-Aldrich (St. Louis, Missouri). Methyl 3phenylpropionate (98\%) was obtained from Alfa Aesar (Wardhill, Massachusetts). Triclosan (irgasan 97\%; Fluka, Ronkonkoma, New York), triphenyl phosphate $(500 \mu \mathrm{g} / \mathrm{mL}$; Protocol, Acros Organics, Morris Plains, New Jersey), ibuprofen (98\%, Sigma-Aldrich, St. Louis, Missouri), and DEET (100 $\mu \mathrm{g} / \mathrm{mL}$; Ultrascientific, North
Kingstown, Rhode Island) were also used. Radio-labeled surrogates; 2,4-dichlorophenol-ring $\mathrm{D}_{3}$ (98\%); bis(2-ethylhexyl)phthalatering- $\mathrm{D}_{4}(98 \%) ; 3,3$ '-dichlorobenzidine-diphenyl- $\mathrm{D}_{6}(98 \%)$; and caffeine-trimethyl-13C3, 99\%) were obtained from Cambridge Isotope Laboratories (Andover, Massachusetts).

Calibration curves were prepared using four concentration levels spanning at least one order of magnitude. All calibration curves had a root mean square of at least 0.95 . The calibration standards were prepared to cover the range of expected concentrations after extraction and concentration from $2000 \mathrm{~mL}$ to $0.5 \mathrm{~mL}$. U.S. Environmental Protection Agency (Washington, D.C.) guidelines (U.S. EPA, 1993) were followed to obtain instrument detection limits (IDLs) and method detection limits (MDLs). The IDLs were 

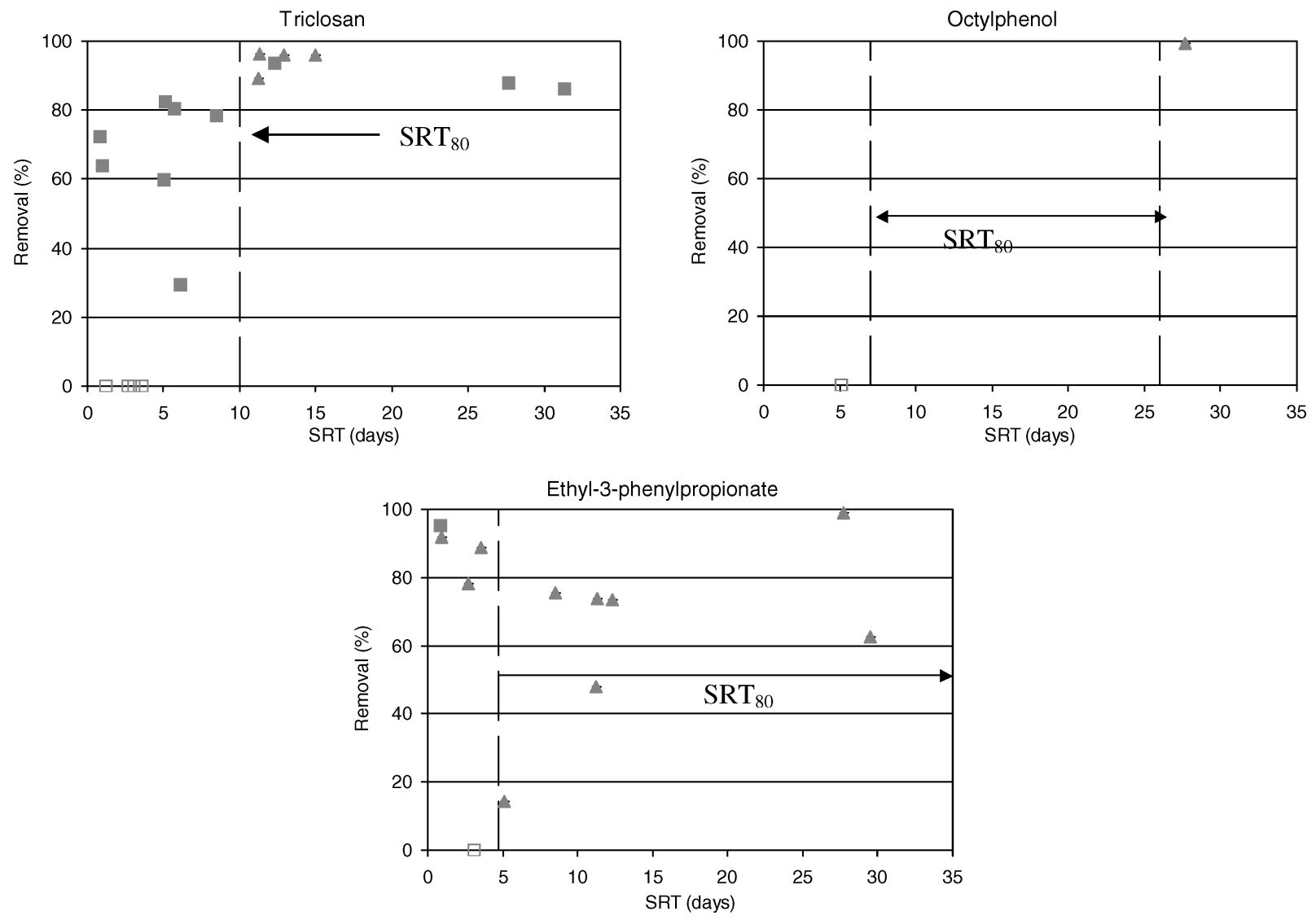

Figure 4-Percent removal in relation to SRT for moderate removal bin compounds $(\boldsymbol{\square}=$ actual removal, $\Delta=$ removal greater than the percentage value presented, and $\square=$ effluent concentration greater than influent concentration).

determined for pure compounds spiked in ethyl acetate. The MDLs were determined by spiking a stock solution containing the surrogates and a mixture of the analytes into aliquots of dual glass-fiber-filtered secondary effluent obtained from a U.S. East Coast treatment facility. A baseline aliquot, extracted and analyzed without the addition of the analytes, provided background concentrations of the target analytes. Table 2 also provides the spiked concentrations, baseline concentrations, calculated MDLs, and ratio of MDL to the initial concentrations. The initial concentrations consisted of the spiked concentration or the spiked concentration plus the baseline concentration whenever the baseline concentration was $20 \%$ or greater than its spiked concentration. Di(ethylhexyl)phthalate was dropped from the study because of high blank contamination from the SPE disks (Loraine and Pettigrove, 2002).

\section{Results and Discussion}

Occurrence Data and Secondary Treatment Performance. Cumulative probability plots of each target PPCP compound for the secondary influent samples were used to classify the compounds into three occurrence bins. Bin definitions, compound assignments, and 50th percentile values are provided in Table 3 . Sixty percent of the compounds occurred frequently, $20 \%$ occurred sporadically, and the remaining $20 \%$ occurred infrequently. There was no correlation between frequency of occurrence and compound octanol-water partition coefficient $\left(K_{\mathrm{ow}}\right)$, an empirical measurement of organic chemical hydrophobicity.
On a few occasions, the effluent concentration was greater than the influent concentration, and this difference sometimes exceeded the relative percentage difference observed for the split samples. The reason this occurs is unknown, but may be the result of such factors as (1) the difference in analytical capabilities for the different matrices, or (2) desorption from the bioreactor solids. When this occurred, the percentage removal was considered to be zero. The definition of treatment performance classifications and assignment of compounds into bins on the basis of observed percentage removals are provided in Table 4. Fifty-five percent of the compounds were well removed, $15 \%$ were moderately removed, and $30 \%$ were poorly removed through secondary treatment. Treatment classification of compounds from the infrequent occurrence bin is limited by insufficient data, as they were seldom detected in the influent. Changes in the influent concentration of the investigated PPCPs with respect to influent flowrates were monitored, but did not seem to affect their removal performance. Also, as shown in Figure 2, no consistent correlation was observed between removal performance and $K_{\mathrm{ow}}$ values of the investigated compounds, which suggests that biodegradation was effective in reducing some low $K_{\text {ow }}$ compounds not amenable to adsorption and that solids adsorption was not sufficient in completely removing some compounds with high $K_{\text {ow }}$ values.

Critical Solids Retention Time Values. Full-scale activated sludge processes are inherently dynamic, because they experience variable conditions of loading and operation. As a result, the true SRT of such systems can be difficult to determine at a given time. 

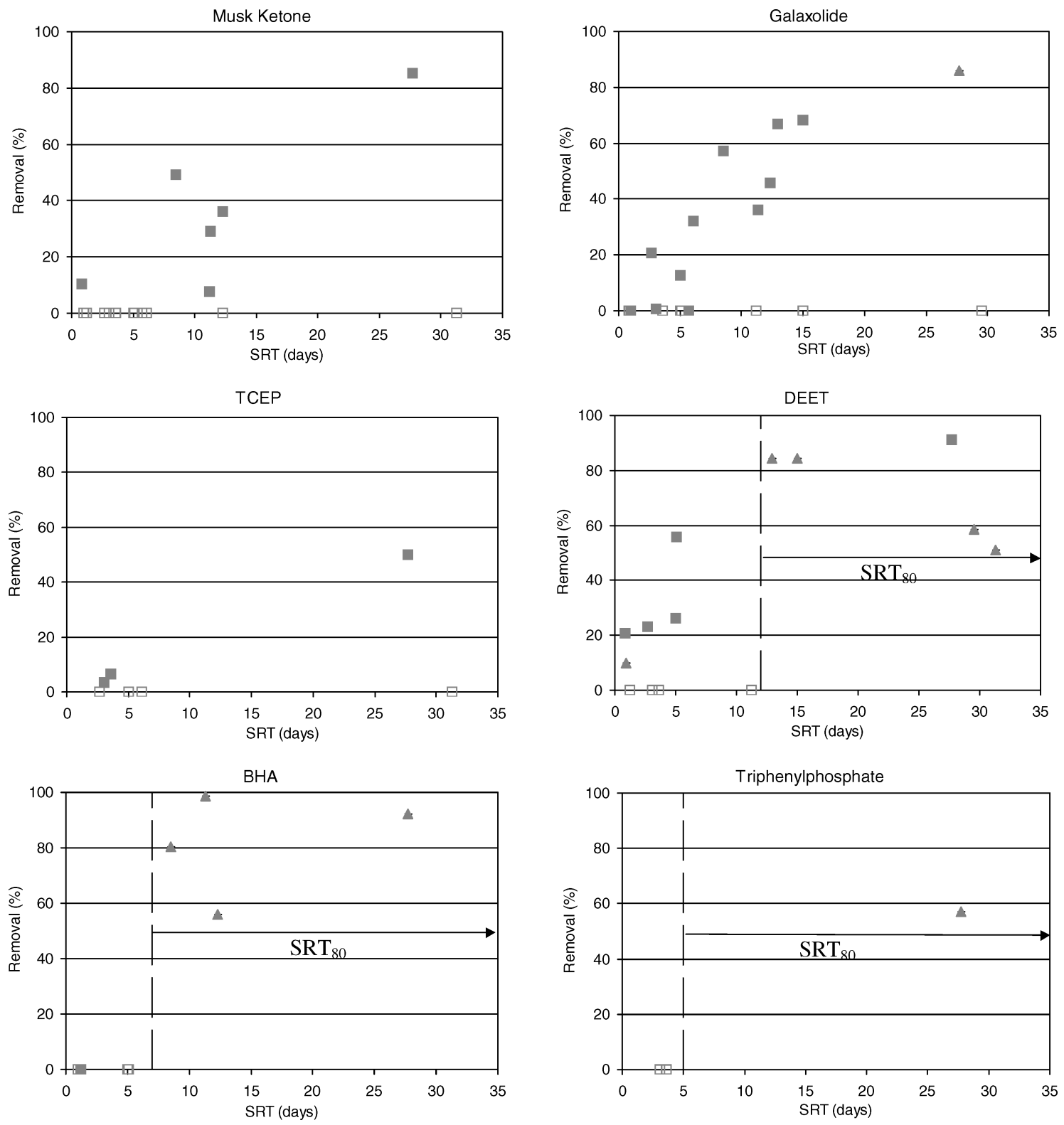

Figure 5-Percent removal in relation to SRT for poor removal bin compounds $(\square=$ actual removal, $\Delta=$ removal greater than the percentage value presented, and $\square=$ effluent concentration greater than influent concentration).

The SRT values reported in this work were provided by the participant facilities and correspond to the daily SRT value calculated by the plant for the date of collection. For this reason, the degree of confidence of the reported SRTs is directly linked to the accuracy of the procedures used by the facilities to generate these values.

Plots of the percentage removal of each target compound versus the SRT of the secondary treatment process were used to define a critical SRT $\left(\mathrm{SRT}_{80}\right)$. The $\mathrm{SRT}_{80}$ represents the minimum SRT value needed to consistently achieve compound removal greater than $80 \%$. For the 11 compounds categorized under the "excellent removal" bin classification (Figure 3), the $\mathrm{SRT}_{80}$ was $<5$ days, with the exception of benzophenone, with an $\mathrm{SRT}_{80}$ of 13 days. Only one of the three compounds categorized under the "moderate removal" bin classification (Figure 4) had sufficient occurrence data to enable determination of $\mathrm{SRT}_{80}$ values to be made. Triclosan required an $\mathrm{SRT}_{80}$ value of 10 days. The compounds in the "poor removal" bin classification (Figure 5) showed the most pronounced dependence on SRT. Musk ketone, galaxolide, and tris(2-chloroethyl)phosphate (TCEP) had $\mathrm{SRT}_{80}$ values in excess of 15 days. The wide variation in removal observed for these compounds at an SRT of 30 days could not be attributed to any apparent differences in plant operations. The good removals were all attained during an October 5 sampling event, and the poor removals were all attained during November 12 or January 9 sampling events (Figure 6). The plant daily effluent discharge temperatures for these dates do not support a seasonal influence on removal, because recorded temperatures were $25.8^{\circ} \mathrm{C}$ on October 5 , $24.4^{\circ} \mathrm{C}$ on November 12 , and $18.9^{\circ} \mathrm{C}$ on January 9. A mass-balance study is needed to assess whether longer SRT values can result in 

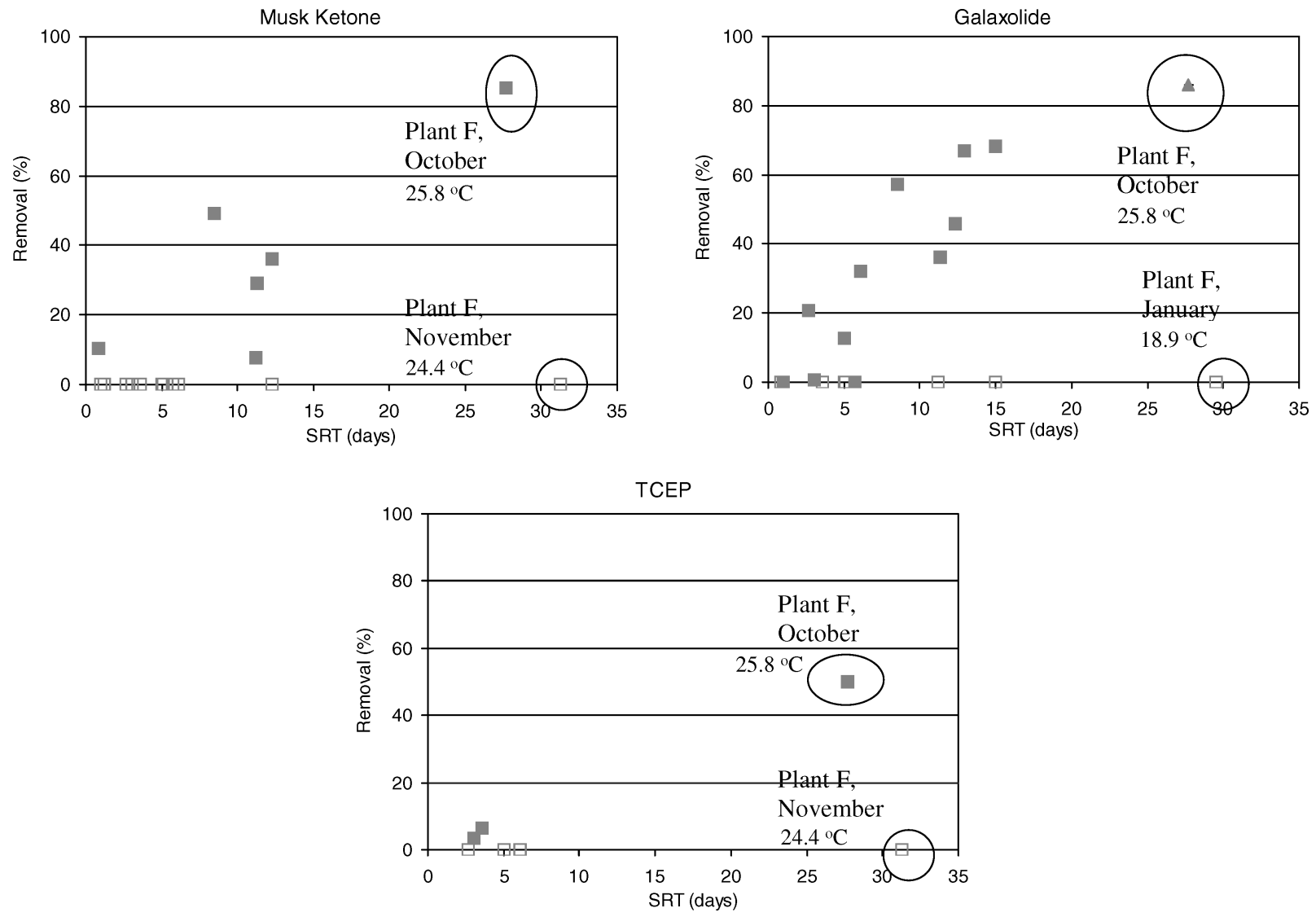

Figure 6-Seasonal variation in the removal of musk ketone, galaxolide, and TCEP in plant $\mathbf{F}(\square=$ actual removal, $\Delta=$ removal greater than the percent value presented, and $\square=$ effluent concentration greater than influent concentration).

desorption from the sludge. At the longer SRT values, the poor removals occurred when influent values were less than twice the MDL, and the good removals occurred when influent values were greater than five times the MDL. Desorption, if occurring, would be more noticeable at low influent conditions and would manifest as a lower percentage removal.

Membrane Bioreactors, Media Filtration, and Membrane Performance. The MBR\#02 was run in parallel with the plant $\mathrm{E}$ activated sludge process using identical influent. Because of the high SRT values of the MBR and the plant (approximately 11 to 15 days), only the compounds with demonstrated $\mathrm{SRT}_{80}$ values in excess of 15 days would be expected to have sufficient levels remaining in the secondary effluent to allow a comparison of percentage removals. Of these compounds, only DEET and galaxolide were detected in the influent during one sampling event. Although the data are limited, the results demonstrate the comparability of performance, with $67 \%$ removal of galaxolide for plant $\mathrm{E}$ and $68 \%$ removal for the MBR. The DEET was reduced below the MDL for both plant E and the MBR. This supports the expectation that ultrafiltration MBR membranes cannot provide an additional benefit of removing PPCP compounds by sieving, as the PPCP molecules are more than 100 times smaller than the pore size of the membranes. These results support previous authors (Clara et al., 2005; Joss et al., 2005).

When PPCP compounds were still detected after secondary treatment, further treatment with media filtration was rarely effective in providing additional removal (Table 5).
In most cases, removal was less than $15 \%$, and sometimes filter effluent values were greater than filter influent values. This may have occurred because the daily composite influent and effluent sample collection was not offset by the hydraulic retention time (HRT) of the filters or because of sloughing of the filter surface biofilm. Only 6 out of 30 observations demonstrated positive removals greater than $25 \%$. These occurred as single events for chloroxylenol $(>42 \%)$, methylparaben $(>97 \%)$, DEET $(26 \%)$, musk ketone $(>55 \%)$, oxybenzone $(>68 \%)$, and triclosan $(67 \%)$. Approximately $50 \%$ of these positive removals occurred during the second sampling event for plant $\mathrm{F}$, and the other $50 \%$ occurred for the first sampling event of plant D. Because the PPCP compounds were only measured in the aqueous phase of the filter influent and filter effluent samples, the demonstration that media filtration contributed little or no removal of these compounds is expected. Reverse osmosis treatment, however, was effective in removing any remaining aqueous phase compounds to less-than-detectable levels. Benzophenone showed low removal after reverse osmosis treatment, but this might be the result of trace contamination in the samples (traces of this compound were present in sampling blank).

Influence of Hydraulic Retention Time. For the majority of participating secondary processes, the HRT correlated well with the SRT (Figure 7). The exceptions occurred for plant E operated below capacity, for one sampling event at plant D during operation at above-average flow, and the two MBR systems. These four systems were operated under similar SRTs (11 to 15 days), but distinct HRTs ( 5 to 30 hours). Comparison of the two compounds with high 
Table 5-Percent removal of PPCPs through tertiary filters and reverse osmosis. ${ }^{a}$

\begin{tabular}{|c|c|c|c|}
\hline РPCP & $\begin{array}{c}\text { Plant F } \\
\text { filter } \\
\text { (\% removal) }\end{array}$ & $\begin{array}{c}\text { Plant D } \\
\text { filter } \\
\text { (\% removal) }\end{array}$ & $\begin{array}{c}\text { Plant D } \\
\text { reverse } \\
\text { osmosis } \\
\text { (\% removal) }\end{array}$ \\
\hline Chloroxylenol & $\begin{array}{c}-27^{\mathrm{b}} \\
0 \\
\mathrm{ND}\end{array}$ & $\begin{array}{c}<-147^{c} \\
>42^{d} \\
\text { ND }\end{array}$ & $>59$ \\
\hline Methylparaben & $\begin{array}{l}>97 \\
\text { ND } \\
N D\end{array}$ & $\begin{array}{l}\text { ND } \\
\text { ND } \\
\text { ND }\end{array}$ & \\
\hline DEET & $\begin{array}{l}26 \\
N D \\
N D\end{array}$ & $\begin{array}{l}-8 \\
N D \\
N D\end{array}$ & $>48$ \\
\hline Benzophenone & $\begin{array}{c}<-88 \\
N D \\
N D\end{array}$ & $\begin{array}{l}-12 \\
-23 \\
N D\end{array}$ & $\begin{array}{r}41^{\mathrm{e}} \\
>38\end{array}$ \\
\hline TCEP & $\begin{array}{c}12 \\
-17 \\
N D\end{array}$ & $\begin{array}{l}\text { ND } \\
-100 \\
N D\end{array}$ & $>65$ \\
\hline Galaxolide & $\begin{array}{l}N D \\
N D \\
-18\end{array}$ & $\begin{array}{c}8 \\
-37 \\
-51\end{array}$ & $\begin{array}{l}>42 \\
>46 \\
>77\end{array}$ \\
\hline Musk ketone & $\begin{array}{c}12 \\
0 \\
N D\end{array}$ & $\begin{array}{l}-2 \\
>55 \\
-20\end{array}$ & $\begin{array}{l}>43 \\
>68\end{array}$ \\
\hline Oxybenzone & $\begin{array}{c}3 \\
0 \\
N D\end{array}$ & $\begin{array}{l}N D \\
>68 \\
N D\end{array}$ & \\
\hline Triclosan & $\begin{array}{c}67 \\
15 \\
N D\end{array}$ & $\begin{array}{l}\text { ND } \\
-27 \\
-74\end{array}$ & $\begin{array}{l}>93 \\
>79\end{array}$ \\
\hline Butylbenzyl phthalate & $\begin{array}{l}-24 \\
>4 \\
N D\end{array}$ & $\begin{array}{l}\text { ND } \\
N D \\
N D\end{array}$ & \\
\hline
\end{tabular}

a Table only presents the compounds that were detected in the secondary effluent; ND = not detected, both in influent and effluent.

${ }^{b}$ Negative percent removal indicates that the filter effluent concentration is greater than the filter influent concentration.

c " $<$ " indicates that the removal is smaller than the percentage value presented, because the influent concentration is below the MDL.

$d ">$ " indicates that the removal is greater than the percentage value presented, because the effluent concentration is below the MDL.

e Low apparent removal, probably because of trace contamination in the sample blank.

$\mathrm{SRT}_{80}$ values that were detected in these plant influents (i.e., galaxolide and musk ketone) have insufficient data to be conclusive, but demonstrate little apparent effect of HRT alone on compound removal through secondary treatment (Figure 8).

\section{Conclusions}

Analysis of influent and effluent samples from six full-scale secondary treatment facilities and two pilot MBR reactors generated a database used to characterize 20 target PPCP compounds into nine categories of occurrence and ease of removal through treatment (Figure 9).

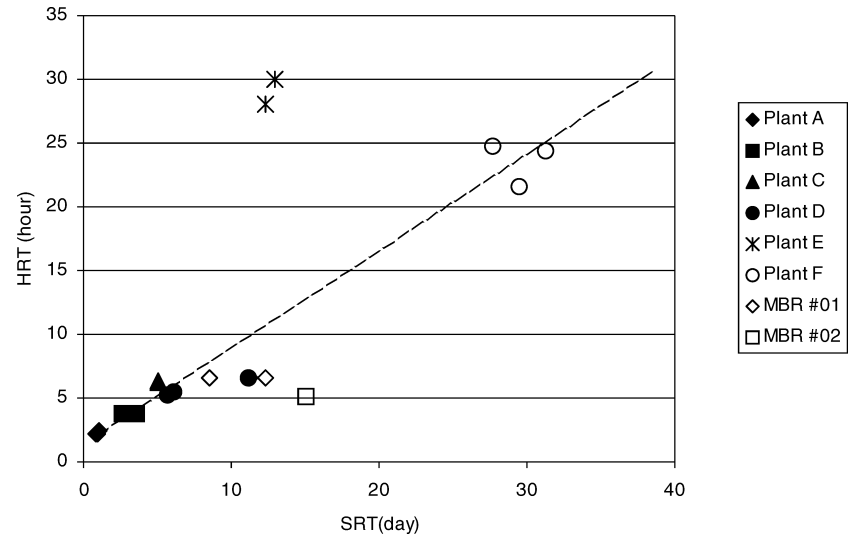

Figure 7-Correlation of HRT and SRT in the sampled secondary treatment systems.

The major conclusions of this study can be summarized as follows:

- $45 \%$ of the 20 PPCP target compounds showed frequent occurrence in secondary influent, but were also well removed $(>80 \%)$ at a critical $\mathrm{SRT}_{80}$ of less than 5 days. These compounds were caffeine, ibuprofen, oxybenzone, chloroxylenol, methylparaben, benzyl salicylate, 3-phenylpropionate, butylbenzyl phthalate, and octylmethoxycinnamate.

- The most problematic compounds are those that occurred frequently, but demonstrated low removals, until a much higher critical $\mathrm{SRT}_{80}$ value was provided. Compounds that occurred frequently and required a critical $\mathrm{SRT}_{80}$ value greater than 15 days were the fragrances musk ketone and galaxolide. Triclosan and benzophenone, while also frequently detected, exhibited a lower critical $\mathrm{SRT}_{80}$ value in the vicinity of 10 to 15 days. Insufficient data were available to characterize the critical $\mathrm{SRT}_{80}$ for DEET and BHA, but it was in excess of 5 days.

- Better removal was not observed for a pilot MBR operated in parallel with a conventional activated sludge system or for an activated sludge system operated at longer HRTs. While little additional removal of target compounds was evident for media filters, reverse osmosis was effective in reducing any remaining target compounds below detection limits.

- Because there are no definitive action levels for the monitored PPCPs, design recommendations based on the findings of this study are not appropriate, at this point. However, the results suggest the potential benefit derived from designing and operating municipal WWTPs at higher SRTs with respect to the fate of these compounds.

\section{Credits}

This work was supported by the Water Environment Research Foundation (Alexandria, Virginia) under contract no. 03-CTS22UR, and the authors would like to thank the WERF Project Manager-Christy Terhune-and members of the Project Advisory Subcommittee-Kenneth Banks, City of Denton (Texas); Rolf Halden, Johns Hopkins University (Baltimore, Maryland); John Novak, Virginia Tech (Blacksburg, Virginia); Neil Parke, Eli Lily \& Co. (Indiananpolis, Indiana); Bernard Sawyer, Metropolitan Water Reclamation District of Greater Chicago (Illinois); and 

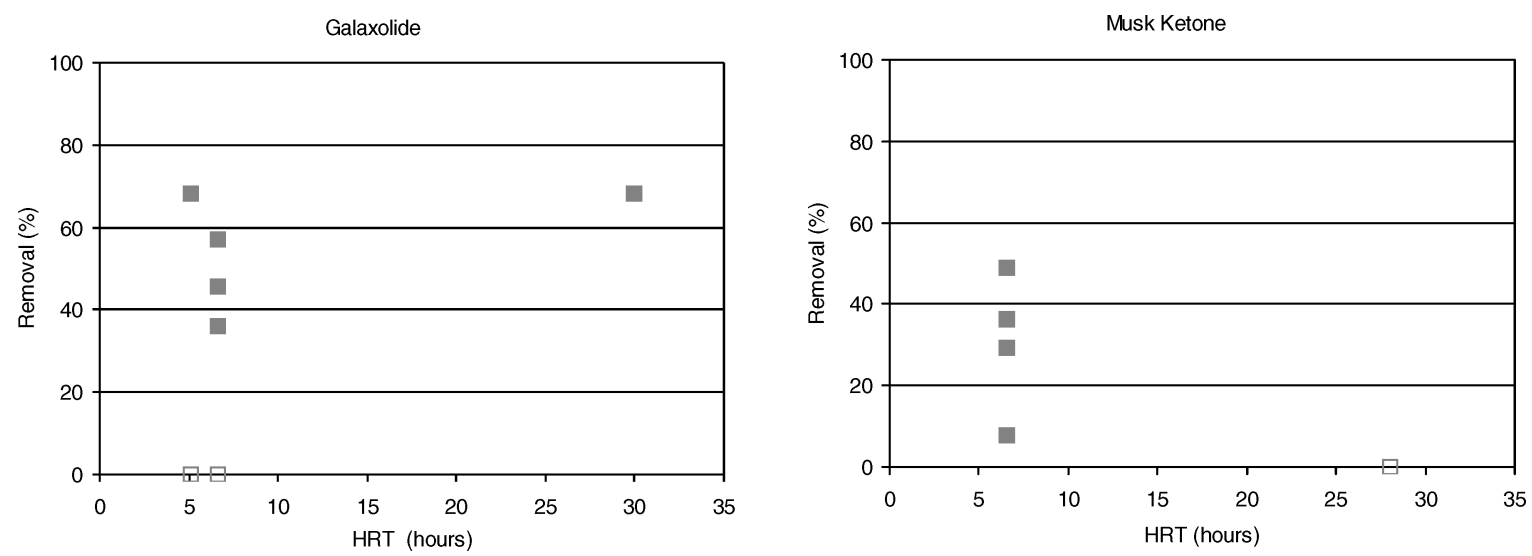

Figure 8-Influence of HRT on percent removal of galaxolide and musk ketone (SRT of 11 to 15 days).

David Sedlak, University of California (Berkeley). Gratitude is also extended to Shane Snyder (Southern Nevada Water Authority) and Rhodes Trussell (Trussell Technologies Inc., Pasadena, California) for their guidance and advice. We also acknowledge the PPCP analytical work provided at the laboratory of Greg Loraine, with Dynaflow Inc. (Jessup, Maryland). We are also indebted to the participating utilities for their support and assistance during this project and to Suvid Surendran of Montgomery Watson Harza (MWH, Pasadena, California) for sample collection.

Submitted for publication June 23, 2006; revised manuscript submitted May 15, 2007; accepted for publication May 21, 2007.

The deadline to submit Discussions of this paper is March 15, 2008.

\begin{tabular}{|c|c|c|c|}
\hline Occurrence & $\begin{array}{c}\text { Bin } \mathrm{T} 1 \\
\text { Excellent removal }\end{array}$ & $\begin{array}{c}\text { Bin } \mathbf{T} 2 \\
\text { Moderate removal }\end{array}$ & $\begin{array}{c}\text { Bin T3 } \\
\text { Poor removal }\end{array}$ \\
\hline $\begin{array}{c}\text { Bin O1 } \\
\text { Infrequent }\end{array}$ & $\begin{array}{c}\text { Methyl-3- } \\
\text { phenylpropionate }\end{array}$ & Octylphenol & $\begin{array}{c}\text { TCEP } \\
\text { Triphenylphosphate }\end{array}$ \\
\hline $\begin{array}{c}\text { Bin } 02 \\
\text { Variable }\end{array}$ & & $\begin{array}{c}\text { Ethyl-3- } \\
\text { phenylpropionate }\end{array}$ & $\begin{array}{c}\text { BHA } \\
\text { DEET } \\
\text { Musk ketone }\end{array}$ \\
\hline $\begin{array}{c}\text { Bin O3 } \\
\text { Frequent }\end{array}$ & $\begin{array}{c}\text { Caffeine } \\
\text { Ibuprofen } \\
\text { Oxybenzone } \\
\text { Chloroxylenol } \\
\text { Methylparaben } \\
\text { Benzyl Salicylate } \\
\text { 3-Phenylpropionate } \\
\text { Butylbenzyl Phthalate } \\
\text { Octylmethoxycinnamate }\end{array}$ & $\begin{array}{c}\text { Triclosan } \\
\text { Benzophenone }^{b}\end{array}$ & Galaxolide \\
\hline
\end{tabular}

aTreatment classification of compounds in this bin is limited by insufficient data, as they were seldom detected in the influent.

${ }^{\mathrm{b}}$ Although benzophenone classified as bin TI based on median removal $>80 \%$, it was moved to bin T2, because it required a much higher $\mathrm{SRT}_{80}$ than the other bin $\mathrm{T} 1$ compounds.

Figure 9-Distribution of target PPCP compounds into occurrence and treatment performance bins. 


\section{References}

Andersen, H.; Siegrist, H.; Halling-Sorensen, B.; Ternes, T. (2003) Fate of Estrogens in a Municipal Sewage Treatment Plant. Environ. Sci. Technol., 37 (18), 4021-4026.

Clara, M.; Kreuzinger, N.; Strenn, B.; Gans, O.; Droiss, H. (2005) The Solids Retention Time-A Suitable Design Parameter to Evaluate the Capacity of Wastewater Treatment Plants to Remove Micropollutants. Water Res., 39 (1), 97-106.

Clara, M.; Strenn, B.; Auusserleitner, M.; Kreuzinger, N. (2004) Comparison of the Behavior of Selected Micropolllutants in a Membrane Bioreactor and a Conventional Wastewater Treatment Plant. Water Sci. Technol., 50 (5), 29-36.

Daughton, C. G.; Ternes, T. A. (1999) Pharmaceutical and Personal Care Products in the Environment: Agents of Subtle Change? Environ. Health Persp., 107 (6), 907-938.

Eriksson, E.; Auffart, K.; Eilersen, A.-M.; Henze, M.; Ledin, A. (2003) Household Chemicals and Personal Care Products as Sources for Xenobiotic Organic Compounds in Grey Wastewater. Water SA, 29 (2), 135-146.

Grady Jr., C. P. L.; Daigger, G. T.; Lim, H. C. (1980) Biological Wastewater Treatment, 2nd ed.; Marcel Dekker Inc.: New York.

Halling-Sørenson, B.; Nors Nielsen, S.; Lanzky, P. F.; Ingerslev, F.; HoltenLützhøft, H. C.; Jergensen, S. E. (1998) Occurrence, Fate and Effects of Pharmaceutical Substances in the Environment-A Review. Chemosphere, 36 (2), 357-393.

Irwin, R. (1998) Source of Chemicals that Feminize Lake Mead Fish Discovered. National Park Service-Year in Review, http://72.14.253. 104/search?q=cache:mQK YftCKnwAJ:www2.nature.nps.gov/ YearinReview/yir98/PDFs/yir1998.pdf+Irwin, +R.+(1998)+National+ Park + Service + Sources + of + Chemicals + that + Feminize + Fish $\&$ $\mathrm{hl}=\mathrm{en} \& \mathrm{ct}=\mathrm{clnk} \& \mathrm{~cd}=2 \& \mathrm{gl}=\mathrm{us}($ accessed spring 2006).

Joss, A.; Andersen, H.; Ternes, T.; Richie, P.; Siegrist, H. (2004) Removal of Estrogens in Municipal Wastewater Treatment Under Aerobic and Anaerobic Conditions: Consequences for Plant Optimization. Environ. Sci. Technol., 38 (11), 3047-3055.

Joss, A.; Keller, E.; Alder, A. C.; Gobel, A.; McArdell, C. S.; Ternes, T.; Siegrist, H. (2005) Removal of Pharmaceuticals and Fragrances in Biological Wastewater Treatment. Water Res., 39, 3139-3152.

Kanda, R.; Griffin, P.; James, H. A.; Fothergill, J. (2003) Pharmaceutical and Personal Care Products in Sewage Treatment Works. J. Environ. Monit., 5, 823-830.

Kolpin, D. W.; Furlong, E. T.; Meyer, M. T.; Thurman, E. M.; Zaugg, S. D.; Barber, L. B.; Buxton, H. T. (2002) Pharmaceuticals, Hormones, and Other Organic Wastewater Contaminants in U.S. Streams, 1999-2000: A National Reconnaissance. Environ. Sci. Technol., 36 (6), 1202-1211.

Kreuzinger, N.; Clara, M.; Droiss, H. (2004) Relevance of the Sludge Retention Time (SRT) as Design Criteria for Wastewater Treatment
Plants for the Removal of Endocrine Disruptors and Pharmaceuticals from Wastewater. Water Sci. Technol., 50 (5), 149-156.

Loraine, G. A.; Pettigrove, M. (2002) Occurrence of Pharmaceuticals and Xenoestrogens in Drinking Water and Wastewater in San Diego, CA. Poster Session, CEA-Crest, 3rd Annual Environmental Science Conference, Pasadena, California, May 3-4; Center for Environmental Analysis, Los Angeles, California.

Ollers, S.; Singer, H.; Fassler, P.; Muller, S. (2001) Simultaneous Quantification of Neutral and Acidic Pharmaceuticals and Pesticides at the Low-ng/l Level in Surface and Wastewater. J. Chrom. A, 911, 225-234.

Osemwengie, L. I.; Steinberg, S. (2001) On-Site Solid-Phase Extraction and Laboratory Analysis of Ultra-Trace Synthetic Musks in Municipal Sewage Effluent Using Gas Chromatography-Mass Spectrometry in the Full-Scan Mode. J. Chrom. A, 932, 107-118.

Sedlak, D. L.; Gray, J.; Pinkston, K. E. (2000) Understanding Microcontaminants in Recycled Water. Environ. Sci. Technol., 34 (23), 508A-515A.

Snyder, E. M.; Snyder, S. A.; Kelly, K. L.; Gross, T. S.; Villaneuve, D. L.; Fitzgerald, S. G.; Villalobos, S. A.; Giesy, J. P. (2004) Reproductive Responses of Common Carp (Cyprinus carpio) Exposed in Cages to Influent of the Las Vegas Wash in Lake Mead, Nevada, from Late Winter to Early Spring. Environ. Sci. Technol., 38, 63856395.

Snyder, S. A.; Westerhoff, P.; Yoon, Y.; Sedlak, D. L. (2003) Pharmaceuticals, Personal Care Products and Endocrine Disruptors in Water: Implications for the Water Industry. Environ. Eng. Sci., 20 (5), 449-456.

Snyder, S.; Kelly, K.; Grange, A.; Sovocool, G. W.; Snyder, E.; Giesy, J. (2001) Pharmaceuticals and Personal Care Products in the Waters of Lake Mead, Nevada. In Pharmaceuticals and Personal Care Products in the Environment-Scientific and Regulatory Issues, Daughton, C., Jones-Lepp, T. (Eds.); American Chemical Society: Washington, D.C.

Ternes, T. A.; Stumpf, M.; Mueller, J.; Haberer, K.; Wilken, R.-D.; Servos, M. (1999) Behavior and Occurrence of Estrogens in Municipal Sewage Treatment Plants-I. Investigations in Germany, Canada and Brazil. Sci. Total Environ., 225, 81-99.

U.S. Environmental Protection Agency (1993) Guidelines Establishing Test Procedures for the Analysis of Pollutants: Procedures for Detection and Quantitation. Appendix B. Definition and Procedure for the Determination of the Method Detection Limit. Code of Federal Regulations, Part 136, Title 40.

Wilson, B. A.; Smith, V. H.; Denoyelles, F.; Jr., Larive, C. K. (2003) Effects of Three Pharmaceutical and Personal Care Products on Natural Freshwater Algal Assemblages. Environ. Sci. Technol., 37 (9), 17131719 . 